\title{
Future Technology Scenarios for Urban Mobility in India
}

\author{
Shankar Venugopal
}

\begin{abstract}
Our ability to ensure clean and convenient mobility in our cities is a key to the sustainable growth of our economy. Volatile fuel prices, rising levels of emissions (and associated problems like smog), and traffic congestions are the key challenges that we face in most Indian cities today. We need the best of our young minds to look at emerging technologies, like smart and connected vehicles, to overcome these challenges. I expect that urban mobility, both personal and commercial, will be shaped by disruptive technologies such as: the move to on-demand mobility, the impact of autonomous vehicles, and the growth of electric vehicles. I will present future technology scenarios and describe technology innovations that could help us to respond to these future scenarios.
\end{abstract}

Keywords Future automotive technologies - Autonomous vehicles • Hybrid electric vehicles - Battery technologies

\footnotetext{
S. Venugopal $(\square)$

Director-Technology Planning and Innovation, Cummins, Chennai, India

e-mail: shankar.venugopal@cummins.com 